\title{
Determination and Use of Phase Diagrams for Rubber- or Thermoplastic-Modified Poly(cyanurate) Networks
}

\author{
ZhiQiang Cao, Françoise Méchin, and Jean-Pierre Pascault* \\ Laboratoire des Matériaux Macromoléculaires, UMR CNRS 5627, \\ Institut National des Sciences Appliquées de Lyon, Bât. 403 \\ 20, Avenue A. Einstein, 69621 Villeurbanne Cedex, France
}

Blends of two cyanate ester monomers [4,4'-dicyanato-1,1-diphenylethane (DPEDC) or 4,4'-dicyanato2,2-diphenylpropane (DCBA)] with several initially miscible reinforcing additives were studied as a function of cyanate conversion. The phase diagrams (temperature vs. conversion for the different transitions: phase separation, gelation, and vitrification) provide a good overview of the systems and allow easy comparisons. DCBA is a better solvent than DPEDC. Rubber systems based on butadieneacrylonitrile have an upper critical solubility temperature (UCST) behavior, whereas poly (ether sulfone)s (PESs) induce a lower critical solubility temperature (LCST) behavior. The acrylonitrile content of the rubbers and the molar mass of the PES additives also have a great influence on their miscibility. During an isothermal cure, phase separation always occurs before vitrification; in rubber it generally occurs before gelation, and in PES it occurs together with gelation. The temperature and viscosity at which phase separation occurs are critical for the final morphology. Reactive additives accelerate the curing process and modify this morphology by inducing a complex matrix-particle interface, and a substructure inside the dispersed particles; these modifications produce the best toughening effects.

Published in ACS : Adv. Chem. Ser. 252 "Toughened Plastics II: Novel Approaches in Science \& Engineering"; Ed. C. K. Riew \& A. Kinloch; Advances in Chemistry; American Chemical Society: Washington, DC, 1996; chap. 13, pp 177-194. 
Brittle thermosets are best toughened by the introduction of a rubbery or thermoplastic dispersed phase (1-4). The dispersed phase can be produced by two methods: in situ reaction and adding preformed particles. The first method is used much more because it is easy and it can create specific morphologies. In the first method, the initial mixture of monomer(s) and additive is homogeneous at the isothermal curing temperature, $T_{\mathrm{i}}$ and the dispersed phase is obtained by the phase separation induced by polycondensation of the monomer(s).

The main factors that determine the degree of toughening are the final polymer blend morphology and the adhesion between the two phases. For initially miscible reactive systems, the first factor (including diameters, number, and volume fraction of the dispersed spherical particles) is determined by the competition between the rates of phase separation and polycondensation. Adhesion between the two phases depends on the chemical and physical properties of both the additive and the monomer (5-8). The phase-separation process induced by the reaction and the formation of the morphology are intricate phenomena; for thermosetting systems, their study is focused mainly on rubber-toughened polyepoxy matrices $(1,3)$. An analysis of the experimental results leads to the following conclusions:

1. The concentration of dispersed particles decreases with $T_{\mathrm{i}}$

2. The volume fraction of dispersed phase, $V_{D}$, remains practically constant, goes through a maximum, or decreases with $T_{i}$

3. The number-average diameter, $\bar{D}$, of the spherical particles increases with $T_{\mathrm{i}}$

4. $\bar{D}$ and $V_{D}$ increase with the initial volume fraction of the additive, $\phi_{a, 0}$

5. But $V_{D}$ is always greater than $\phi_{a, 0}$. This fact means that the dispersed phase is not formed only of pure rubber additive, $\mathrm{R}$, but also contains some epoxy-amine copolymer. It can be about $50 \mathrm{wt} \%$. A second phase separation has been demonstrated to occur inside the dispersed particles. (9)

On the other hand, the initial miscibility of the monomer(s) with the additive has a great influence on both the phase separation and the final morphologies. Many experimental results (5-10) show that phase separation occurs well before gelation time, $t_{\mathrm{gel}}$, or conversion, $x_{\mathrm{gel}}$, and before vitrification ( $t_{\text {vit, }}$, $x_{\text {vit }}$. The better the initial miscibility, the higher the conversion at the cloud point, $x_{c p}$, where the phase separation induced by polycondensation occurs at a given value of $T_{\mathrm{i}}$. Initial miscibility and $T_{\mathrm{i}}$ control the "chemical quench". The viscosity at the cloud point, $\eta_{c p}$, obviously increases with the conversion, $x_{c p}$. The viscosity, $\eta_{c p}$, can affect the nucleation and growth of the dispersed-phase particles and consequently their average diameter $(6,11)$, and sometimes also the shape of the particles, which is not necessarily spherical.

Cyanate ester (CE) resins are the key monomers for a new type of high-performance polymer. They were developed by Hi-Tek Polymers during the 1980s, then Rhône-Poulenc, and now Ciba-Geigy. The polycyclotrimerization of cyanates can take place by simple heating, or it can be catalyzed by transition metal cations together with labile hydrogen compounds, phenols, alcohols, or amines (12).

Like epoxy systems, CE systems can be toughened with (1) engineering thermoplastics (13-18), including polysulfones or poly(ether sulfone)s, polyimides, and polyesters or polyarylates, and (2) rubbers, including butadiene-acrylonitrile copolymers (13), polysiloxanes (14), and preformed particles $(15,16)$. We can conclude that the different concepts, rubber- or thermoplastic-modified thermosets, 
work as well with CE as with epoxy. But unlike epoxy, only a few results in the literature give relations between the initial miscibility of monomer and additive, the curing conditions, and the morphologies and properties. This chapter examines the influence of rubber and thermoplastic additives (nature and end groups) on polymerization kinetics and, mainly, on the evolution of phase diagrams. Work on morphologies and properties is examined elsewhere (19).

\section{Experimental Methods}

Monomers. The CE monomers, 4,4'-dicyanato-1,1-diphenylethane (DPEDC) and dicyanate of bisphenol A (DCBA), were provided by Ciba-Geigy (Louisville, KY) in reference Arocy L10 and Arocy B10, and were used as received. Liquid DPEDC contains 2-3\% impurities (trimer, monophenolmonocyanate, and ortho-para-substituted isomers). DCBA is a high-purity (>99.5\%) crystalline powder (melting temperature $79^{\circ} \mathrm{C}$ ). The chemical structures of these monomers are shown in Chart I.

Additives. Acrylonitrile-butadiene rubbers were provided by BFGoodrich (Brecksville, $\mathrm{OH}$ ). The amino-terminated butadiene-acrylonitrile (ATBN) rubber was obtained by reacting carboxylterminated butadiene-acrylonitrile (CTBN) with an excess diamine, Unilink 4200 (from UOP, El Dorado Hills, CA); consequently, free diamine molecules always remained in the rubber. The rubbers have almost the same molar mass but different end groups, which have been characterized in a previous work (20). Their structures are given in Chart I, and they are described in Table I. The two poly(ether sulfone)s (PESs) (Victrex, from ICl, United Kingdom) used in this study are described in Table II.

The two PES additives have different molar masses and different concentrations of phenolic end groups. By ${ }^{1} \mathrm{H}-\mathrm{NMR}$ spectroscopy we have estimated that PES4100P is an unreactive oligomer, in contrast to PES5003P, which has approximately one $\mathrm{OH}$ per molecule.

Preparation of the Blends. The CE blends, which contain 15 wt\% additive, were prepared by manual stirring at room temperature for rubber additives, and with dichloromethane as a solvent for PES additives.

Polymerization Reaction. The differential scanning calorimetry (DSC) pan, containing 10-15 mg of sample, was sealed under air. It was then placed in the oven at $180^{\circ} \mathrm{C}$, and the reaction allowed to proceed. In order to measure the temperature at the cloud point, $T_{\mathrm{cp}}$, during polymerization, about 2 $\mathrm{g}$ of sample in a test tube was isothermally polymerized in situ inside the light-transmission device (21).

Cure of Plates. In an oven, $240 \mathrm{~g}$ of blend in a 6 -mm-thick mold was precured at 180,150 , or $120^{\circ} \mathrm{C}$ for a time necessary to arrest the phase separation, and then it was postcured with the same cycle at higher temperatures until completion of the polycondensation of CE monomer without any degradation. The evolution of the real temperature of the plate was followed by use of a thermocouple. 
<smiles>CC(c1ccc(OC#N)cc1)c1ccc(OC#N)cc1</smiles>

DPEDC, $264 \mathrm{~g} / \mathrm{mol}$<smiles>CC(C)(C#N)[P]C(C)(C)C#N</smiles>

NFBN<smiles>CC(C)(c1ccc(OC#N)cc1)c1ccc(OC#N)cc1</smiles>

DCBA, $278 \mathrm{~g} / \mathrm{mol}$

CTBN

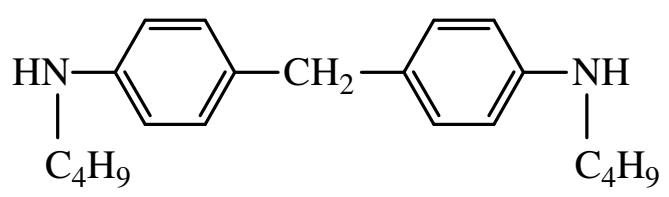

Unilink 4200
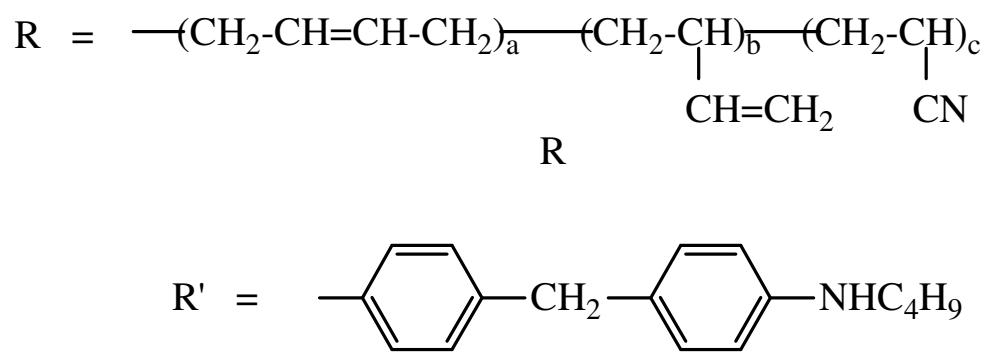

$\mathrm{R}^{\prime}$

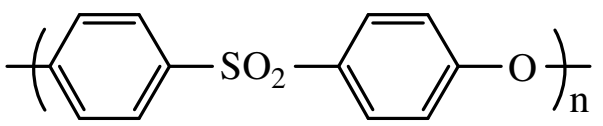

PES additive

Chart 1. Chemical structures and characteristics of dicyanate monomers, elastomer additives, and PES additives

Analytical Techniques. The cloud point of the blends was determined with a light-transmission device (21). Once the blend was cloudy, the test tube was taken out and chilled in ice, so that the time and conversion at the cloud point, $t_{\mathrm{cp}}$ and $x_{\mathrm{cp}}$ could be obtained. The $\mathrm{T}_{\mathrm{g}}$ value and conversion were measured by DSC (Mettler TA3000 microcalorimeter) (22). The gel time, $t_{\mathrm{gel}}$, of rubber-cyanate blends was determined as the time at which insolubles appeared in tetrahydrofuran (THF). That of PEScyanate was determined by dynamic mechanical analysis (Rheometrics RDA700). 
We observed the fracture surfaces using a scanning electron microscope (SEM, JEOL 840A) after coating them with a gold sputterer. Transmission electron micrographs (TEMs) were obtained by using a JEOL 1200 device for ultramicrotomed samples. Using a procedure previously described (23), we calculated the following parameters:

$$
\begin{gathered}
\text { number-average diameter: } \bar{D}=\frac{\sum n D}{\sum n} \\
\text { volume fraction of the dispersed phase: } V_{D}=(\pi / 4) \frac{\sum n D^{2}}{A_{T}}
\end{gathered}
$$

where $A_{T}$ is the total area of the micrograph region under analysis.

Tensile and compressive tests were performed at room temperature with a tensile testing machine (DY25, Adamel-Lhomargy). For the tensile tests, strain measurements were performed with an extensometer (EX-10) at a strain rate of $3.3 \times 10^{-4} \mathrm{~s}^{-1}$, using ISO-60 standard specimens. Samples of dimension $20 \times 12 \times 6 \mathrm{~mm}$ were deformed in a compression cage between polished steel plates. The nominal strain was determined by averaging the results from two linear variable differential transformer (LVDT) transducers. The strain rate used was $8.3 \times 10^{-4} \mathrm{~s}^{-1}$.

Fracture toughness was studied with opening mode I tests and in a plane strain rate. The samples were loaded to failure using a crosshead speed of $1 \mathrm{~mm} / \mathrm{min}\left(5.2 \times 10^{-4} \mathrm{~s}^{-1}\right)$, at room temperature. Values for the critical stress intensity factor, $K_{\mathrm{lc}}$, were calculated by using the following formula:

$$
K_{I c}=\sigma_{c} \sqrt{\pi a} Y\left(\frac{a}{w}\right)
$$

where $\sigma_{c}$ is the critical fracture stress, $a$ is the crack length, and $w$ is the specimen width. The correction factor is given by:

$$
Y\left(\frac{a}{w}\right)=1.09-1.735 \frac{a}{w}+8.2\left(\frac{a}{w}\right)^{2}-14.18\left(\frac{a}{w}\right)^{3}+14.57\left(\frac{a}{w}\right)^{4}
$$

Once $K_{\mathrm{lc}}$ was determined, the fracture energy, $G_{\mathrm{lc}}$, was calculated with Young's modulus and the Poisson coefficient, which were determined experimentally for every formulation following usual procedures.

Table I. Characteristics of the Elastomer Additives

\begin{tabular}{|c|c|c|c|c|}
\hline Characteristic & NFBN & CTBN & ATBN & Unilink 4200 \\
\hline Functionality & 0 & $1.8(\mathrm{COOH})$ & $1.9\left(\mathrm{NHR}^{\prime}\right)$ & $2.0\left(\mathrm{NHC}_{4} \mathrm{H}_{9}\right)$ \\
$\%$ AN & 17.2 & 18.0 & 18.0 & 0 \\
$\overline{M_{n}}(\mathrm{~g} / \mathrm{mol})$ & 3600 & 3600 & $3600+10 \%$ excess Unilink 4200 & 310 \\
$\overline{M_{w}} / \overline{M_{n}}$ & $2.1^{a}$ & $1.9^{a}$ & $2.8(\text { polymer peak })^{a}$ & 1.0 \\
$T_{\mathrm{g}}\left({ }^{\circ} \mathrm{C}\right)$ & -67 & -60 & -47 & $-{ }^{b}$ \\
\hline
\end{tabular}

NOTE: Chemical structures are shown in Chart I.

${ }^{a}$ From size-exclusion chromatography measurements (polystyrene standards).

${ }^{b}$ Not measured 
Table II. Characteristics of the PES Additives

\begin{tabular}{|c|c|c|c|}
\hline Reference & ${\overline{\boldsymbol{M}_{\boldsymbol{n}}}}^{a}$ & $\overline{\boldsymbol{M}_{\boldsymbol{w}}} / \overline{\boldsymbol{M}}_{\boldsymbol{n}}$ & $\boldsymbol{T}_{\mathrm{g}}\left({ }^{\circ} \mathrm{C}\right)^{\boldsymbol{b}}$ \\
\hline PES4100P & 15,200 & 2.7 & 216 \\
PES5003P & 21,900 & 2.1 & 222 \\
\hline
\end{tabular}

NOTE: The chemical structure of PES is shown in Chart I.

${ }^{a}$ From size-exclusion chromatography measurements in dimethylformamide at $80^{\circ} \mathrm{C}$.

${ }^{b}$ From DSC measurements.

\section{Results and Discussion}

Initial Miscibility of the Blends. In Figure 1, we have plotted the cloud-point curves obtained with the following substances:

1. two rubbers with the same percentage of acrylonitrile (AN):

- a nonfunctional rubber, nonfunctional butadiene-acrylonitrile (NFBN)

- a carboxy-terminated rubber, CTBN

2. two different reactive monomers:

- a CE, DPEDC

- bisphenol A diglycidyl ether, DGEBA (DER 332 from Dow)

All the blends have an upper critical solubility temperature (UCST) behavior. It is evident that the CE monomer is a better solvent of rubbers than the epoxy prepolymer.

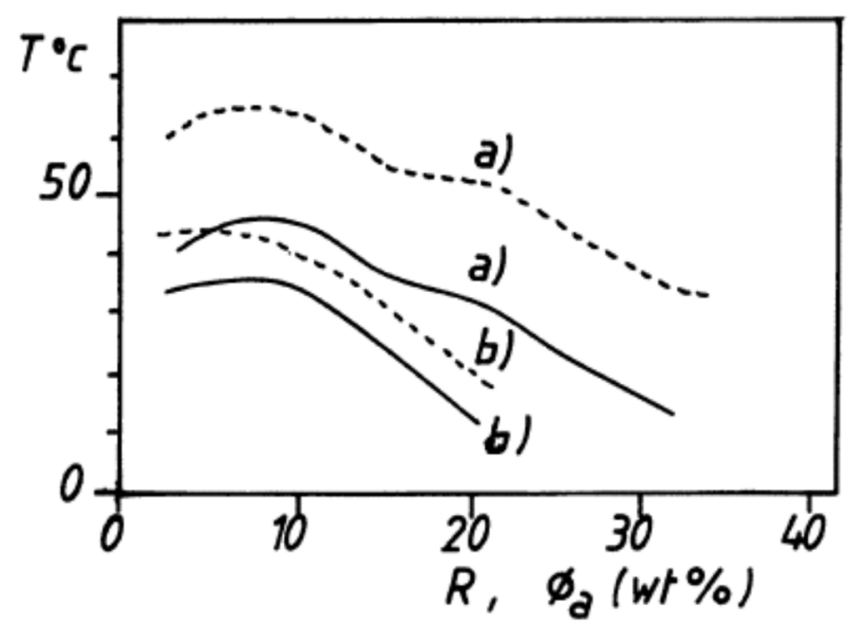

Figure 1. Initial cloud-point curves for rubber-DGEBA (DER 332) (- - -) and rubber-DPEDC (Arocy L10) $(--)$, with NFBN rubber (a) and CTBN rubber (b). $R$ is rubber, and $\phi_{a}$ is mass fraction

The NFBN rubber is less miscible than the CTBN rubber. An amino-terminated rubber, ATBN8, with the same amount of AN , $18 \mathrm{wt} \%$, is quite miscible with DPEDC or DGEBA, showing that chain ends of reactive liquid oligomers can have a strong effect on their miscibility (20). Finally, by decreasing the 
percentage of AN, the miscibility window decreases drastically (21). For example, ATBN31, with only $10 \mathrm{wt} \% \mathrm{AN}$, is quite immiscible with DPEDC and DGEBA at temperatures lower than $100^{\circ} \mathrm{C}$.

PES is miscible with DGEBA or DPEDC at room temperature, and PES-DGEBA blends have a lower critical solubility temperature (LCST) behavior (Figure 2). But because of CE reactions at temperatures greater than $100^{\circ} \mathrm{C}$, the comparison between CE and DGEBA is not possible.

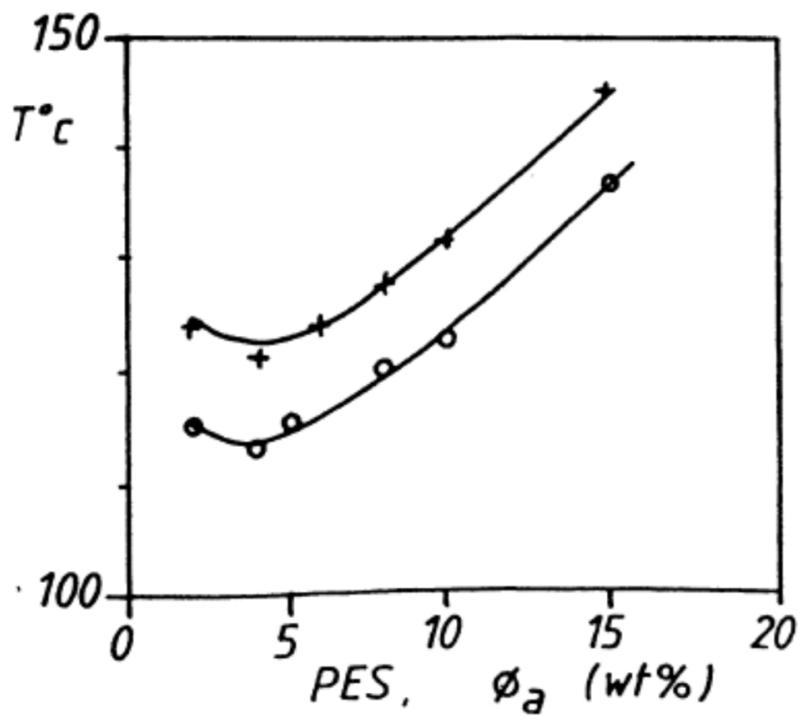

Figure 2. Initial cloud-point curves for PES-DGEBA (DER 332). Key: +, PES4100P; and O, PES5003P.

Polymerization. To plot the evolution of the phase diagram, it is necessary to have a good knowledge of the reaction rates and conversions at different isothermal curing temperatures. These kinetic parameters were determined in a previous study (22), using $T_{\mathrm{i}}=180^{\circ} \mathrm{C}$ for systems based on DPEDC, and $T_{\mathrm{i}}=200^{\circ} \mathrm{C}$ for those based on DCBA (which is less reactive). Our experiments revealed that in the first part of the curing process, that is, as long as it remained kinetically controlled, the unreactive additives (with respect to the cyanate functions, i.e., NFBN, CTBN, and PES4100P) did not modify the overall kinetics compared with the neat monomer. Systems based on DCBA could be modeled (24) by the following equation:

$$
\begin{aligned}
\frac{d x}{d t}= & k_{1}(1-x)^{2}+k_{2} x(1-x)^{2} \\
& \text { second order } \quad \text { second order autocatalyzed }
\end{aligned}
$$

Equation 3 is often used in the literature to account for the kinetic behavior of several common dicyanate monomers $(25,26)$. The autocatalytic character of cyanate polycyclotrimerization is now quite well established; we noticed that it was especially enhanced in samples with a large surface directly exposed to air $(24,27,28)$. The kinetics of DPEDC blends were more difficult to describe because they were perturbed by several residual impurities in the monomer. Together with adventitious air moisture, the latter increased gel conversion with respect to the theoretical value (0.5).

In contrast to these unreactive modifiers, the additives that were likely to react with cyanates (ATBN via its secondary amine function, and PES5003P via its phenol function) were shown to appreciably accelerate their cure, even in its very first steps. Phenols (12) usually react with cyanates to yield iminocarbonates; the latter are generally proposed as intermediates in the polycyclotrimerization mechanism: 


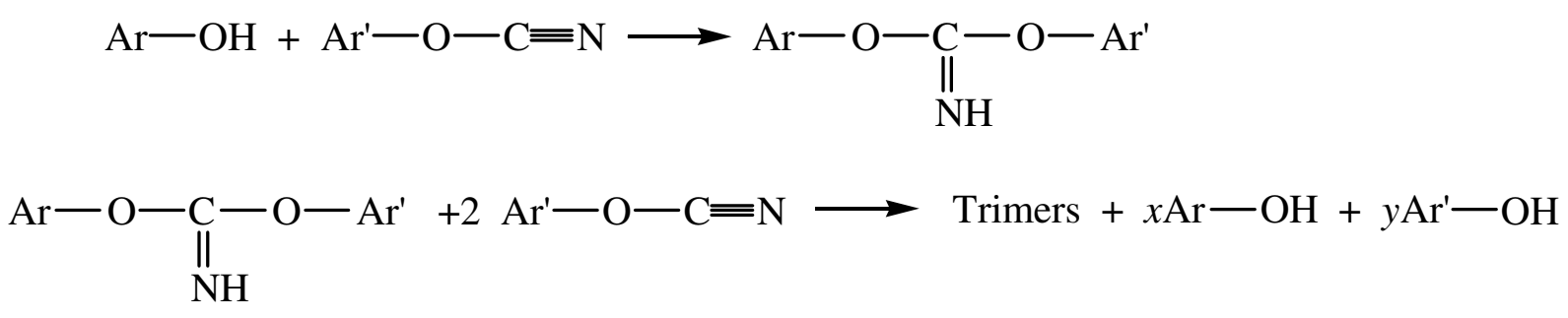

In our group (29), experiments run with model monofunctional phenols confirmed these possible first steps. The same kind of studies (29) were carried out with a monofunctional aromatic amine and suggested that in ATBN, the following reactions could presumably be involved:

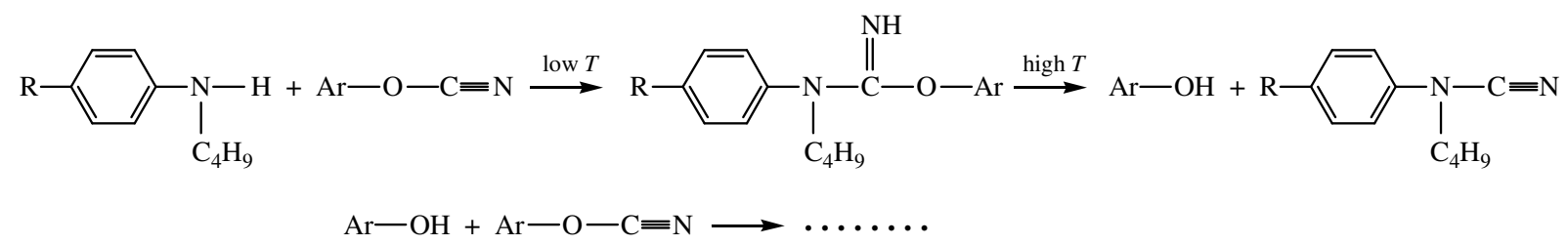

These reactions could explain the reaction activation observed for the blends of DPEDC with PES5003P and ATBN, especially as the latter also contains excess free diamine. Considering the $10 \%$ residual Unilink 4200 in ATBN, we determined the reaction rate associated with a 1.74\% Unilink 4200-DPEDC blend, which simulates the concentration of the excess free Unilink 4200 in a 15-wt\% ATBN8-DPEDC blend. The results are not presented here, but in the presence of Unilink 4200, DPEDC reacted faster, in the same range of reactivity as ATBN-Unilink (22).

All the rubber or thermoplastic-modified cyanates studied were initially miscible at the curing temperature, $T_{\mathrm{i}}$. At a certain conversion, phase separation occurred as the molar mass of the cyanate oligomers increased and more polar cyanate functional groups were transformed into less-polar cyanurate rings. The phase-separation phenomena could be observed simply by the fact that the solution became cloudy (cloud point). We measured the conversions at which the isothermally cured blends became cloudy $\left(x_{\mathrm{cp}}\right)$ and the gel conversions $\left(x_{\mathrm{gel}}\right)$; the $x_{\mathrm{gel}}$ values were practically the same for neat systems and blends, considering experimental error. For all the blends, phase separation occurred well before gelation. Therefore, we conclude that in these cases phase separation did not disturb the polymerization kinetics or the network buildup.

For PES4100P and PES5003P, the conversions at the cloud point were respectively 0.44 and 0.40 for $T_{\mathrm{i}}=180{ }^{\circ} \mathrm{C}$. Once again, we conclude that phase separation is unlikely to influence the polycyclotrimerization kinetics.

Finally, we noticed that in the last stages of the reaction, in contrast to the neat systems for which vitrification limited the conversion to about 0.9 at $T_{\mathrm{i}}=180^{\circ} \mathrm{C}$, the conversion of all the rubber-modified systems easily reached 0.95 or more, a result indicating that the vitrification effect was delayed and suggesting that part of the rubber dissolved in the matrix and decreased its $T_{\mathrm{g}}(t)$. The same conclusion could be drawn from the glass-transition temperatures of the final networks $\left(T_{\mathrm{g} \infty}\right)$, which are displayed in Table III. Such an effect was not observed for the Unilink 4200-DPEDC mixture (without rubber).

Moreover, the maximum conversion of the 15-wt\% PES5003P-DPEDC blend was lower than that of the 15-wt\% PES4100P-DPEDC blend. This difference was attributed to the possible reactions between additive chain ends and cyanate monomer: the mass fraction of PES5003P dissolved in the matrix after phase separation may be higher than that of PES4100P; thus the vitrification of the former occurs earlier. 
Evolution of Phase Diagrams. The increase in the molar mass of the cyanate ester with conversion obviously modifies the phase diagram of blends. The evolution of phase diagrams of nonfunctional rubber was first studied.

At $T_{\mathrm{i}}=180{ }^{\circ} \mathrm{C}$ for NFBN-DPEDC and at $T_{\mathrm{i}}=200{ }^{\circ} \mathrm{C}$ for NFBN-DCBA (isothermal polymerization), the conversions, $x_{c p}$, where blends with different fractions of additive became cloudy, were measured. Figure 3 shows that the evolution of $x_{\mathrm{cp}}$ with the additive fraction is weak, and $x_{\mathrm{cp}}$ is always lower than the gel conversion of the cyanates, about 0.6. For a polymer blend with two components, the free energy of mixing per unit volume of blend can be expressed by the Flory-Huggins equation. Elsewhere (30), we estimate the Flory-Huggins interaction parameter $\chi$ by fitting the experimental points.

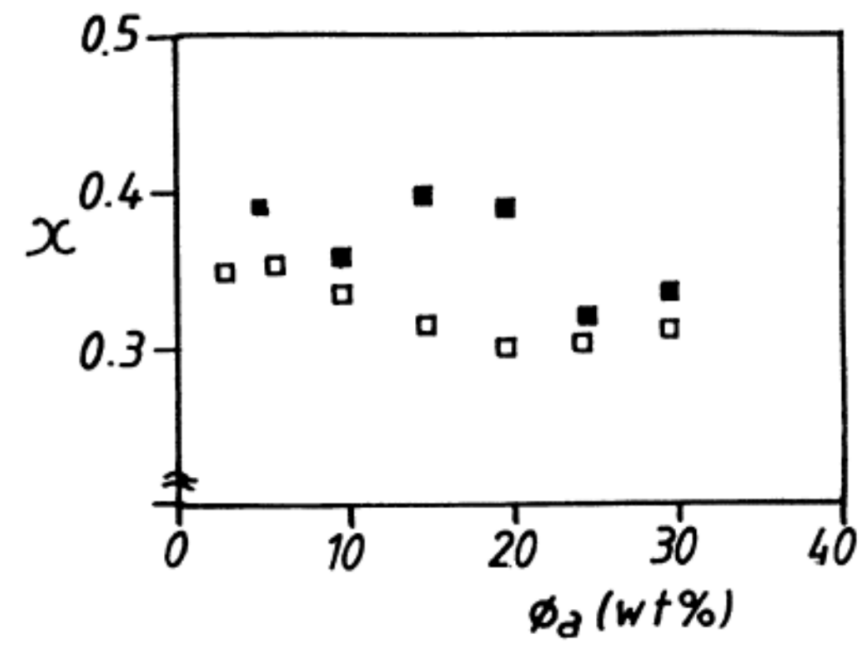

Figure 3. Experimental phase diagram showing conversion $(x)$ versus the mass fraction of rubber $\left(\phi_{\mathrm{a}}\right)$. The rubber is NFBN. Key: $\square, \mathrm{DPEDC}, T_{\mathrm{i}}=180^{\circ} \mathrm{C}$; and $\square, \mathrm{DCBA}, T_{\mathrm{i}}=200^{\circ} \mathrm{C}$

For a given fraction of additive, the $T$ versus $x$ phase diagrams would be more useful for practical applications and for better control of the phase-separation process. In these phase diagrams, it is possible to plot the three transformations together: phase separation, $T_{\mathrm{cp}}$ versus $x_{\mathrm{cp}}$; gelation, $x_{\mathrm{gel}}=$ 0.6 ; and vitrification, $T_{\mathrm{g}}$ versus $x$.

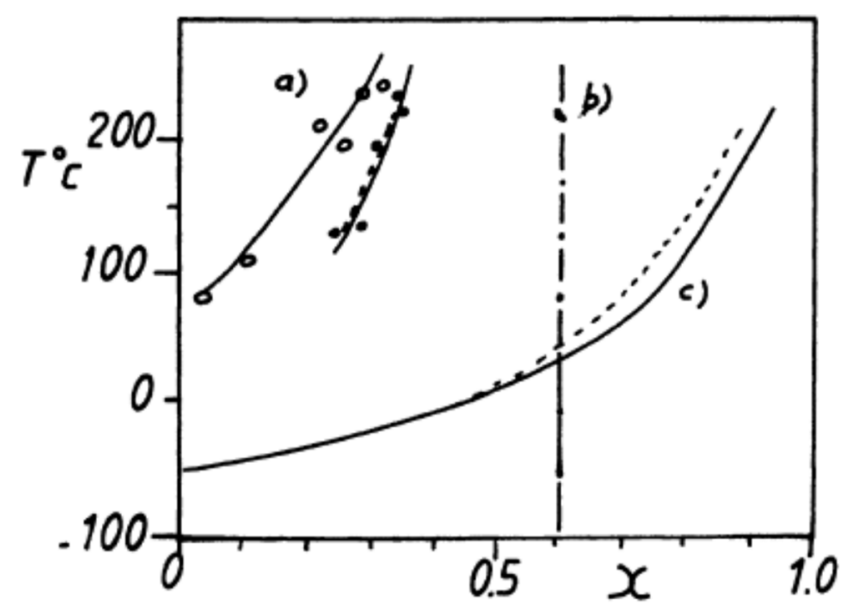

Figure 4. Experimental phase diagram showing temperature versus conversion. Key: $O$, DPEDCNFBN (15 wt\%); 9 , DCBA-NFBN (15 wt\%); a, phase separation; b, gelation ( $x \approx 0.6)$; and c, vitrification $\left(T_{\mathrm{g}}\right)$ versus $x$. 
A 15-wt\% NFBN-DPEDC blend at $T_{\mathrm{i}}=180{ }^{\circ} \mathrm{C}$, and a 15 -wt\% NFBN-DCBA blend at $200{ }^{\circ} \mathrm{C}$ were isothermally polymerized until a certain conversion, then cooled until the blends became cloudy. (Cooling was achieved by simply stopping the heating of the oven in the light-transmission device. The cooling rate depends on the temperature of the oven.) In this way, $T_{\mathrm{cp}}$ and the corresponding $x_{\mathrm{cp}}$ were obtained. Figure 4 shows that the increase in $T_{\mathrm{cp}}$ seems to be linear with respect to $x$ (in the range of $T_{\mathrm{i}}$ studied, because in fact it is an ascending concave curve), which agrees with the UCST-type initial phase diagrams of the blends. On the other hand, at the same $T_{c p}$, the $x_{c p}$ of NFBN-DCBA is always higher than that of NFBN-DPEDC, which means that DCBA is a better solvent for NFBN than DPEDC.

Furthermore, the evolution of $T_{\mathrm{g}}$ for the continuous phase of the blends can be plotted in the same figure for both the 15-wt\% NFBN-DPEDC and 15-wt\% NFBN-DCBA blends (Figure 4). It appears that at a given $x, T_{\text {cp }}$ is always higher than $T_{\mathrm{g}}$. In other words, during an isothermal cure, phase separation occurs before vitrification of the blends. Figure 4 also shows that $x_{c p}$ is always lower than $x_{\text {gel }}$ for $T<220^{\circ} \mathrm{C}$.

To study the influence of rubber reactivity on phase separation, we also measured the phase diagrams of the blends with rubbers ATBN8 and CTBN. As in the 15-wt\% NFBN blend, for the blends with ATBN8 and CTBN, the overall $T$ versus conversion phase diagrams, including phase separation $\left(T_{\mathrm{cp}}, x_{\mathrm{cp}}\right)$, gelation $\left(x_{\text {gel }} \approx 0.6\right)$, and vitrification $\left(T_{\mathrm{g}}, x\right)$ can be plotted (Figure 5). At one isothermal curing temperature, $T_{\mathrm{i}}$, it appears that $x_{\mathrm{cp}}$ is in the order ATBN8 $>$ CTBN $>$ NFBN. This result is consistent with the order of the initial miscibilities of the rubbers with DPEDC.

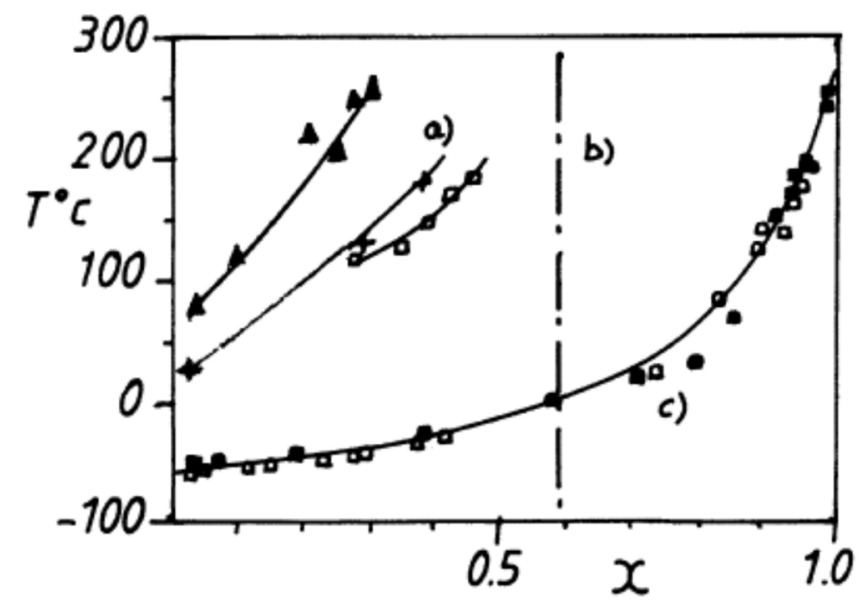

Figure 5. Experimental phase diagram showing temperature versus conversion for rubber ( $15 \mathrm{wt} \%)$ DPEDC blends. Key: $\triangle$, NFBN; +, CTBN; $\square$, ATBN8. Curves (a), (b), and (c) are defined as in Figure 4.

To isolate these different effects, we did the same experiments with 15-wt\% ATBN rubber by replacing small amounts of ATBN8 with ATBN31, which contains only 10\% AN (compared with $18 \%$ AN in the former) and seems to be immiscible with DPEDC. Figure 6 shows that the AN content of ATBN had a drastic effect on the miscibility of ATBN with DPEDC. Similarly, Chen et al. (20) found that the miscibility of CTBN with DGEBA decreased with the decrease in the AN content of the rubber. 


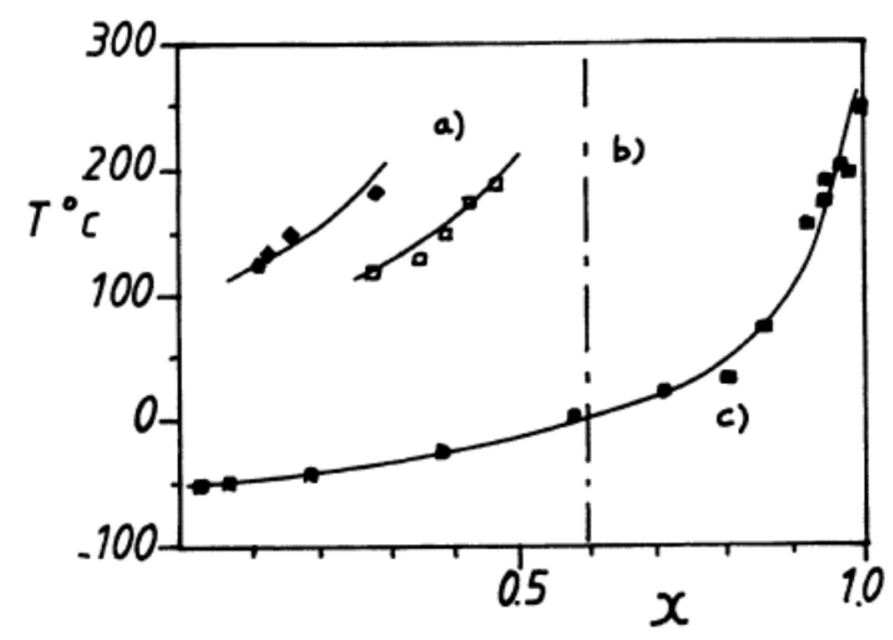

Figure 6. Experimental phase diagram showing temperature versus conversion for rubber (15 wt\%)DPEDC blends. Key: $\square$, ATBN8; and $\diamond$, ATBN8-ATBN31 (5 wt\% in the rubber blend). Regions (a), (b), and (c) are defined as in Figure 4.

Figure 7 shows that in contrast to rubber-DPEDC blends, $T_{\text {cp }}$ decreases almost linearly as $x$ increases (once again in the range of $T_{i}$ studied, because in fact it is a descending concave curve). This result confirms that the PES-CE blends show LCST behaviors. Moreover, the $T_{\mathrm{cp}}$ versus $x$ curve of the 15\% PES4100P-DPEDC blend is to the left of that of the 15\% PES5003P-DPEDC blend. These results indicate that PES4100P is more miscible with DPEDC than PES5003P, which is consistent with the fact that PES4100P has a smaller molar mass.

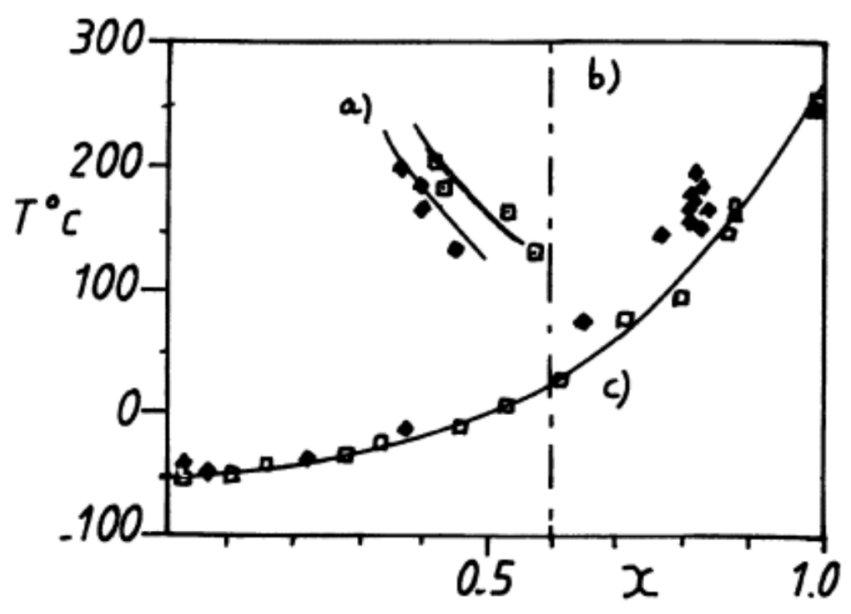

Figure 7. Experimental phase diagram showing temperature versus conversion for PES (15 wt\%)DPEDC blends. Key: $\diamond$, PES5003P; and $\square$, PES4100P.

In addition, the evolution of $T_{\mathrm{g}}$ of the continuous phase of the blends can be plotted in Figure 7 with the $T_{\mathrm{cp}}$ versus $x$ phase diagram. Once again, phase separation occurs before the vitrification of the blends. For a sample cured at $90^{\circ} \mathrm{C}$, phase separation is expected in the same range as gelation $\left(x_{\mathrm{cp}} \approx\right.$ $\left.x_{\text {gel }}\right)$, and in fact no phase separation is observed. Pellan and Bloch (31) also reported that this blend was always clear when precured at $90{ }^{\circ} \mathrm{C}$, even when this precuring up to gelation was followed by a postcuring at $200{ }^{\circ} \mathrm{C}$. We think that this observation results from high viscosity during polymerization and gelation of the system. 
Table III. Phase-Separation Process, Morphologies, and Properties for Neat or Modified Poly(cyanurate) Networks

\begin{tabular}{|c|c|c|c|c|c|c|c|c|c|}
\hline Reactive system & $\mathbf{X}_{c p}$ & $\mathrm{X}_{\text {gel }}$ & $\eta_{c p}$, Pa.s & $\bar{D}, \mu m$ & $\mathrm{~T}_{g \infty},{ }^{\circ} \mathrm{C}$ & $\mathrm{K}_{l c}, M P a \sqrt{m}$ & $\mathrm{G}_{l c}, \mathrm{~J} / \mathrm{m}^{2}$ & $\mathrm{E},{ }^{a} \mathrm{GPa}$ & $\sigma_{y}{ }^{b} M P a$ \\
\hline Neat DPEDC & $-^{c}$ & 0.63 & - & - & 268 & 0.71 & 148 & 3.00 & 138 \\
\hline 1.74 wt\% Unilink-DPEDC & - & - & - & - & 263 & 0.82 & 250 & 2.40 & 136 \\
\hline 15 wt\% NFBN-DPEDC & 0.32 & 0.61 & 0.015 & $7.2 \pm 0.5$ & 260 & 0.87 & 470 & 1.43 & 68 \\
\hline 15 wt\% ATBN8-DPEDC & 0.47 & 0.61 & 0.2 & $1.8 \pm 0.2$ & 248 & 1.40 & 840 & 2.00 & 100 \\
\hline 15 wt\% PES5003P-DPEDC & 0.40 & 0.59 & 1.0 & $1.1 \pm 0.2$ & 246 & 1.06 & 390 & 2.55 & 128 \\
\hline
\end{tabular}

NOTE: Blends were procured at $180^{\circ} \mathrm{C}$ for $2 \mathrm{~h}$ and postcured at $260^{\circ} \mathrm{C}$.

${ }^{a} \mathrm{E}$, Young's modulus.

${ }^{b} \sigma_{y}$, yield stress.

${ }^{c}$ Not measured. 
Morphologies and Properties. The phase diagrams of temperature versus conversion (or vs. time) are useful for controlling the curing of a blend. We said in the introduction that the morphologies are mainly controlled by the temperature, $T_{c p}$, or the viscosity, $\eta_{c p}$, at which phase separation occurs. Generally, when $T_{c p}$ decreases or $\eta_{c p}$ (or $x_{c p}$ ) increases, the dispersed particles become smaller. In Figure 8 we show a series of micrographs obtained by scanning electron microscopy of the fracture surfaces of different samples. Samples are blends of DPEDC and different additives. They were precured at $T_{\mathrm{i}}=180^{\circ} \mathrm{C}$ to control phase separation and gelation, then postcured at high temperature $\left(260^{\circ} \mathrm{C}\right)$ in order to reach full conversion $(x \approx 1)$. As we saw in the phase diagrams, the conversion $\left(x_{\mathrm{cp}}\right)$ or viscosity $\left(\eta_{c p}\right)$ at the cloud point depends on the additive used (Table III).

Table III shows the following: With NFBN, $x_{\mathrm{CP}} \approx 0.30$ and the particles are spherical and large $(\bar{D} \approx 7 \mu \mathrm{m})$. With ATBN, on the other hand, $x_{\mathrm{cp}} \approx 0.47$ and the particles are smaller $(\bar{D} \approx 1.7 \mu \mathrm{m})$, but they also have like a branch substructure. In this case, we expect to see not only an effect of the viscosity but certainly also of the reaction between the rubber and cyanate functions before network formation.

Furthermore, with PES5003P, $x_{\mathrm{cP}} \approx 0.40$ and the particles are also smaller than with NFBN. We also see an effect of the viscosity and of the reactive chain ends of the thermoplastic. But because $T_{\mathrm{i}}$ is $180{ }^{\circ} \mathrm{C}$, which is lower than the $T_{\mathrm{g}}$ of the thermoplastic, one important effect is certainly also the vitrification of the dispersed particles when phase separation occurs. The consequence is that only with thermoplastic additives is an evolution of the morphology observed between precuring and postcuring processes.

With the help of these phase diagrams, it is now possible to define different precuring and postcuring schedules. The effects of the curing process on the final morphologies are presented elsewhere (19).

The introduction of any additive improves the toughness of the material; in particular, $K_{\mathrm{lc}}$ of ATBN8DPEDC is more than twice that of neat DPEDC . In contrast, different additives result in different losses in Young's modulus, from $17 \%$ to $50 \%$, and different losses in the final material glass-transition temperature compared with neat DPEDC (Table III). The fact that $T_{\mathrm{g}}$ is lower for ATBN8- or PES5003Pbased materials than for those obtained with NFBN obviously indicates that with the latter, the continuous phase contains smaller amounts of additive because of poorer miscibility. However, the residual fraction of PES in the final matrix $\left[\left(\phi_{\mathrm{a}}\right)_{\mathrm{m}} \infty\right]$ calculated from Fox's equation for the PES5003PDPEDC blend is above the maximum theoretical value. Thus, we believe that the decrease in $T_{\mathrm{g}}$ for the PES5003P-DPEDC blend results not only from the presence of residual additive but also from the modification of the poly(cyanurate) network because of a possible reaction between PES5003P and DPEDC.

In fact, the system with 15-wt\% ATBN8 has the best-balanced properties of all the modified systems in this study: This sample shows an excellent improvement of the toughness without too large of a loss in $T_{\mathrm{g}}$ and in the modulus, while the system based on NFBN has worse mechanical properties. 

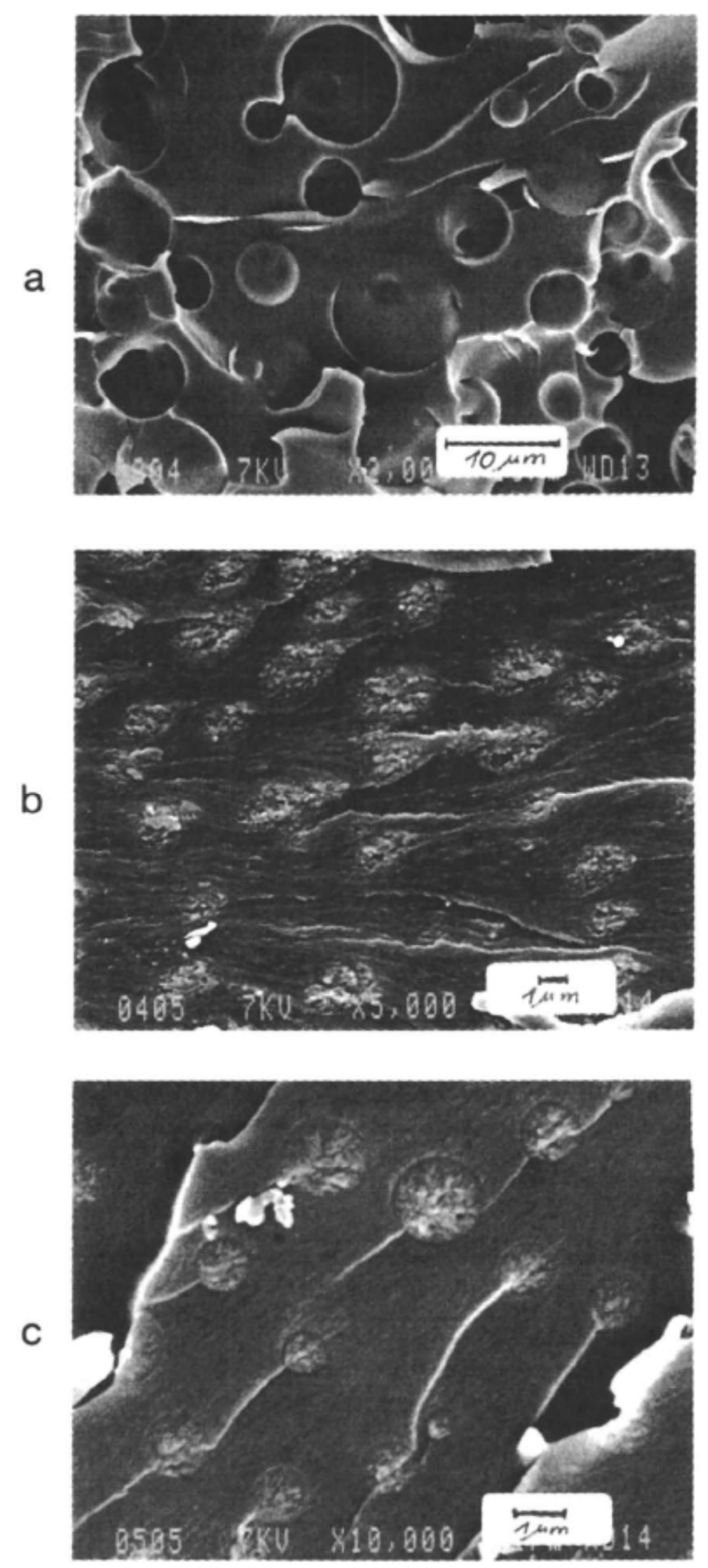

Figure 8. SEM images of the fully cured materials. Part a: 15 wt\% NFBN-DPEDC. Part b: 15 wt\% ATBN8-DPEDC. Part c: 15 wt\% PES5003P-DPEDC. 


\section{Conclusions}

Rubbers and PESs are initially miscible with cyanate ester monomers. Phase separation occurs during the reaction. By plotting the phase diagrams (temperature vs. conversion), it is possible to compare the effects of chain ends and $A N$ content in butadiene-acrylonitrile random copolymers and the effect of molar mass in PES. The cyanate ester monomer based on bisphenol $A$ is a better solvent than DPEDC, and both dicyanates are better solvents than DGEBA.

With the use of phase diagrams, we are also able to control the temperature and the viscosity at which phase separation occurs. The final morphologies of the three systems based on the same dicyanate monomer and modified with NFBN, ATBN, and PES are quite different and have different interfaces. When the additive can react with the monomer before network formation, a two-level structure is observed: a primary structure (dispersed particles), and a substructure inside the dispersed particles. The complex morphology obtained in this case gives the best toughening effect.

\section{References}

1. Rubber Modified Thermoset Resins; Riew, C. K.; Gillham, J. K., Eds.; Advances in Chemistry 208; American Chemical Society: Washington DC, 1984; and references therein.

2. Rubber-Toughened Thermosetting Polymers in Structural Adhesives-Developments in Resins and Primers; Kinloch, A. J., Ed.; Applied Science Publishers: London, 1980; Chapter 5, pp. 127-162.

3. Rubber-Toughened Plastics; Riew, C. K., Ed.; Advances in Chemistry 222, American Chemical Society: Washington DC, 1989; and references therein.

4. Toughened plastics I: Science and Engineering; Riew, C. K.; Kinloch, A. J., Eds.; Advances in Chemistry 233, American Chemical Society: Washington DC, 1993.

5. Williams, R. J. J.; Borrajo, J.; Ababbo, H. E.; Rojas, A. J. In Rubber Modified Thermoset Resins; Riew, C. K.; Gillham, J. K., Eds.; Advances in Chemistry 208, American Chemical Society: Washington DC, 1994; pp. 195-213.

6. Montarnal, S.; Pascault, J. P.; Sautereau, H. In Rubber-Toughened Plastics; Riew, C. K., Ed.; Advances in Chemistry 222, American Chemical Society: Washington DC, 1989; pp. 193-224.

7. Verchère, D.; Sautereau, H.; Pascault, J. P.; Moschiar, S. M.; Riccardi, C. C.; Williams, R. J. J. In Toughened plastics I: Science and Engineering; Riew, C. K.; Kinloch, A. J., Eds.; Advances in Chemistry 233, American Chemical Society: Washington DC, 1993; pp. 335-363.

8. Rozenberg, B. A. Makromol. Chem. Macromol. Symp. 1991, 41, 165-177.

9. Chen, D.; Pascault, J. P.; Sautereau, H.; Vigier, G. Polym. Int., 1993, 32, 369-379.

10. Manzione, L. T.; Gillham, J. K.; McPherson, C. C. J. Appl. Polym. Sci. 1981, 26, 889-907.

11. Ruseckaite, R. A.; Hu, L. J.; Riccardi, C. C.; Williams, R. J. J. Polym. Int. 1993, 30, 287.

12. Grigat, E.; Pütter, R. Angew. Chem. Int. Ed. 1967, 6(3), 206-218.

13. McConnell, V. P. Adv. Compos. 1992, May-June. 
14. Arnold, C.; McKenzie, P.; Malhotra, V.; Pearson, D.; Chow, N.; Hearn, M.; Robinson, G. Proceedings of the 37th International SAMPE Symposium; Society for the Advancement of Material and Process Engineering: Covina, CA 1992; pp. 128-136.

15. Yang, P. C.; Pickelman, D. M.;, Woo, E. P. Proceedings of the 35th International SAMPE Symposium; Society for the Advancement of Material and Process Engineering: Covina, CA 1990; p. 408.

16. Yang, P. C.; Woo, E. P; Laman, S. A.; Jakylowsld, J. J.; Pickelman, D. M.; Sue, H. J. Proceedings of the 36th International SAMPE Symposium; Society for the Advancement of Material and Process Engineering: Covina, CA 1991, p. 437.

17. Shimp, D. A.; Christenson, J. R. Plastic-Metal-Ceramics; Hornfeld, H. L., Ed.; Society for the Advancement of Material and Process Engineering: Switzerland, 1990; pp. 81-93.

18. Srinivasan, S. A.; McGrath, J. E. High Perform. Polym. 1993, 5, 259-274.

19. Cao, Z. Q.; Mechin, E; Pascault, J. P. ACS Polym. Mater. Sci. Eng. Div. Prepr. 1994, 71, 752-753.

20. Chen, D.; Pascault, J. P.; Bertsch, R. J.; Drake, R. S.; Siebert, A. R. J. Appl. Polym. Sci. 1994, 51, 1959.

21. Verchère, D.; Sautereau, H.; Pascault, J. P.; Moschiar, S. M.; Riccardi, C. C.; Williams, R. J. J., Polymer 1989, 30, 107.

22. Cao, Z. Q.; Mechin, F.; Pascault, J. P. Polym. Int. 1994, 34, 41-48.

23. Verchère, D.; Sautereau, H.; Pascault, J. P.; Moschiar, S. M.; Riccardi, C. C.; Williams, R. J. J. J. Appl. Polym. Sci. 1990, 41, 467.

24. Georjon, O.; Galy, J.; Pascault, J. P. J. Appl. Polym. Sci. 1993, 44, 1441.

25. Gupta, A. M. Macromolecules 1991, 24, 3459-3461.

26. Simon, S. L.; Gillham, J. K. J. Appl. Polym. Sci. 1993, 47, 461.

27. Mirco, V.; Cao, Z. Q.; Méchin, F.; Pascault, J. P. ACS Polym. Mater. Sci. Eng. Div. Prepr. 1992, 66, 451.

28. Mirco, V.; Méchin, F.; Pascault, J. P. ACS Polym. Mater. Sci. Eng. Div. Prepr. 1994, 71, 688-689.

29. Mirco, V. PhD Thesis, INSA de Lyon, 1995.

30. Borrajo, J.; Riccardi, C. C.; Williams, R. J. J.; Cao, Z. Q.; Pascault, J. P. Polymer 1995, 36, 3541-3547.

31. Pellan, L.; Bloch, B. In C.-R.Journ. Natl. Comp. 1992, November, 161-172. 